\title{
Transthoracic Echocardiography and 6-Minute Walk Test in Kuwaiti Sickle Cell Disease Patients
}

\author{
Rajaa Marouf $^{a} \quad$ Nasser Behbehani $^{b}$ Mohammed Zubaid ${ }^{b}$ Hanan Al Wazzan ${ }^{d}$ \\ Hadeel El Muzaini $^{a} \quad$ Rasha Abdulla $^{a}$ Olusegun A. Mojiminiyi ${ }^{a}$ \\ Adekunle D. Adekilec \\ Departments of a Pathology, ${ }^{\mathrm{b}}$ Medicine and ${ }^{\mathrm{C}}$ Pediatrics, Faculty of Medicine, Kuwait University, and ${ }^{\mathrm{d}}$ Ministry of \\ Health - Kuwait, Safat, Kuwait
}

\section{Key Words}

Hemoglobinopathies $\cdot$ Sickle cell disease $\cdot$ Tricuspid regurgitant jet velocity - Echocardiography · Pulmonary hypertension

\begin{abstract}
Objective: The aim of this study was to investigate cardiac abnormalities in Kuwaiti sickle cell disease (SCD) patients using markers such as tricuspid regurgitant jet velocity (TRJV), pulmonary artery systolic pressure (PASP), and the 6-minute walk (6MW) test and correlate these findings with clinical, hematological, and biochemical parameters. Materials and Methods: Seventy-three patients with SCD and 70 matched controls were studied. The cardiac status was investigated using transthoracic echocardiography in 57 patients; the $6 \mathrm{MW}$ test was carried out in patients and controls. Complete blood counts and hemolytic parameters were assessed. Results: Reticulocytes, bilirubin, and lactate dehydrogenase were significantly higher $(p<0.0001)$ in patients, while hemoglobin $(\mathrm{Hb})$ and haptoglobin were lower $(p<0.0001)$ than in controls. The mean fetal $\mathrm{Hb}$ among patients was $15.85 \pm 8.7 \%$. Of the 57 patients, 14 (24.5\%) and 15 (26\%) had mild tricuspid and mitral regurgitation, respectively. The
\end{abstract}

mean ejection fraction, TRJV, and PASP were $63.9 \pm 6.3 \%, 1.7$ $\pm 0.5 \mathrm{~m} / \mathrm{s}$, and $23.0 \pm 7.3 \mathrm{~mm} \mathrm{Hg}$, respectively. Three (5.2\%) patients had mildly raised TRJV $(2.6-2.97 \mathrm{~m} / \mathrm{s}$, normal range $<2.5 \mathrm{~m} / \mathrm{s}$ ) while $8(14 \%)$ had high PASP (mean $35.3 \pm 5.1 \mathrm{~mm}$ $\mathrm{Hg}$, normal range $<30 \mathrm{~mm} \mathrm{Hg}$ ). $\mathrm{Hb}$, hematocrit, and reticulocytes were different $(p=0.010, p=0.006$, and $p=0.011$, respectively) between patients with normal and high PASP. All 3 patients who had a high TRJV had a high PASP, and 2 of these patients died during follow-up. The systolic and diastolic blood pressure, oxygen saturation before and after the $6 \mathrm{MW}$ test, and distance walked were lower $(p=0.006, p=0.000$, $p=0.002, p=0.000$, and $p=0.000$, respectively) in patients compared to controls. Conclusion: Raised PASP was common in Kuwaiti SCD patients while raised TRJV was not.

(c) 2014 S. Karger AG, Basel

\section{Introduction}

Pulmonary vasculopathy is associated with pulmonary hypertension (PHT) in sickle cell disease (SCD), contributing significantly to its mortality, especially as more patients survive into adulthood. It has been shown that mortality due to PHT occurs at a higher rate in SCD pa-

\begin{tabular}{ll}
\hline KARGER & $\begin{array}{l}\text { () 2014 S. Karger AG, Basel } \\
1011-7571 / 14 / 0233-0212 \$ 39.50 / 0 \quad \text { Karger }\end{array}$ \\
$\begin{array}{l}\text { E-Mail karger@karger.com } \\
\text { www.karger.com/mpp }\end{array}$ & $\begin{array}{l}\text { This is an Open Access article licensed under the terms of the } \\
\text { Creative Commons Attribution-NonCommercial 3.0 Un- } \\
\text { ported license (CC BY-NC) (www.karger.com/OA-license), } \\
\text { applicable to the online version of the article only. Distribu- } \\
\text { tion permitted for non-commercial purposes only. }\end{array}$
\end{tabular}

Dr. Rajaa Marouf Kuwait University PO Box 24923

Safat 13110 (Kuwait)

E-Mail r-marouf@hsc.edu.kw 
tients compared to controls and with a lower degree of PHT [1]. The pathophysiology of this disease is related to the nitric oxide (NO) scavenging that follows the release of cell-free hemoglobin $(\mathrm{Hb})$ from hemolysis. This leads to vasoconstriction, platelet activation, and upregulation of multiple adhesion molecules. The release of arginase further compromises the available substrate for the production of NO in endothelial cells. Repeated episodes of these hypoxic events are characterized by ischemia-reperfusion injury with progressive tissue damage, an altered pulmonary vascular tone, and vascular proliferation in the arterial smooth muscle wall. Eventually, obliterative pulmonary vasculopathy occurs with PHT.

Right-sided cardiac catheterization is the gold standard for the diagnosis of PHT [2], but it is an invasive procedure. Echocardiographic indices of PHT are based on changes such as right ventricular dilatation, paradoxical motion of the ventricular septum, peak tricuspid valve regurgitant jet velocity (TRJV), and pulmonary artery systolic pressure (PASP). The reliability of this echocardiographic technique has been shown in selective cardiac catheterizations comparing the two techniques in patients with SCD [1]. PASP can be estimated noninvasively using Doppler techniques, and when an acceptable TRJV is obtained these estimates show excellent correlation with invasively determined PASP [3].

The 6-minute walk $(6 \mathrm{MW})$ test is an objective evaluation technique for functional exercise capacity and it is also useful as a noninvasive screening test for PHT. It reflects the functional exercise level for daily physical activities [4]. This test has also been used as a one-time measure of the functional status of SCD patients, as well as as a predictor of morbidity and mortality [5]. Postwalk dyspnea and fatigue levels estimated using the Borg scale are recorded and the total distance a patient can walk in $6 \mathrm{~min}$ is calculated [4].

Although SCD is a monogenic disease, it exhibits considerable phenotypic variability and its expression is modified by several other genetic factors, the most important of which include the $\beta$-globin cluster haplotype, the a-globin genotype, and the fetal $\mathrm{Hb}(\mathrm{HbF})$ level. SCD is relatively common in Kuwait due to a preponderance of consanguineous marriages [6], but it is relatively mild among Kuwaiti patients because they carry the Arab/India $\beta^{S}$ haplotype, which is associated with a high $\mathrm{Hb} \mathrm{F}$ level [7]. Many of the complications [stroke, splenic dysfunction, leg ulcers, priapism, and acute chest syndrome (ACS)], except avascular necrosis and regional brain perfusion deficit, are not common in these patients $[8,9]$. Silent brain infarcts have been shown in only about $3 \%$ of children aged $<16$ years but in up to $20 \%$ of adults [10]. Moreover, the frequency of the $\alpha$-thalassemia trait is about 30\% [11]. There has, however, not been any previous study of PHT in this group of patients. The aim of this study was to investigate cardiac abnormalities in Kuwaiti SCD patients using parameters such as TRJV, PASP and the 6MW test as indirect markers of PHT and correlate the results with clinical, hematological, and biochemical parameters.

\section{Materials and Methods}

\section{Patients and Controls}

For this case control study, consecutive SCD patients (HbSS or $S \beta^{0}$-thalassemia) presenting between 2009 and 2011 to the Hematology Clinic, Mubarak Al Kabeer Hospital, Kuwait, were studied. Seventy-three SCD patients ( 37 males and 36 females) and 70 (36 males and 34 females) age- and sex-matched controls were studied. $\mathrm{The} \mathrm{Hb}$ genotype was confirmed by high-performance liquid chromatography. The inclusion criterion was patients in stable condition, i.e. without acute illness or a crisis in the preceding 4 weeks. Histories of hypertension, diabetes mellitus, smoking status, and asthma were documented. Informed voluntary consent was obtained from all study participants. Age- and sex-matched, apparently healthy controls were recruited from volunteers including workers in the medical school and among the patients' friends and relatives. This study was approved by the Institutional Ethics Committee and was carried out in accordance with the Helsinki Declaration of 1975, as revised in 2008 [12].

\section{Clinical Data}

Age, sex, height, weight, and blood pressure were obtained from patients and controls. The following parameters were documented for the patients: frequency of vaso-occlusive crises and hospital admissions, blood transfusions, ACS, history of splenectomy, leg ulcers, stroke, and treatment with hydroxyurea.

Patients were classified into 2 groups, i.e. severe and nonsevere, depending on how frequently they had vaso-occlusive crises. Those who were hospitalized on more than 3 occasions or who had more than 6 emergency room visits for pain in a year were classified as severe. At least 1 episode of ACS was considered a positive history of ACS.

\section{Laboratory Data}

Blood was obtained from both patients and controls by venipuncture in a fasting state. A complete blood count, including reticulocytes and red blood cell indices, was performed on an automated hematology analyzer (Beckman-Coulter LH 750; BeckmanCoulter, Brea, Calif., USA) and the Hb analysis was done using a cation exchange high-performance liquid chromatograph (Bio-Rad VARIANT II Hemoglobin Testing System; USA). Fasting blood sugar, renal function tests (electrolytes, urea, and creatinine) and liver function tests (total bilirubin, alanine transaminase, alkaline phosphatase, $\gamma$-glutamyltransferase, total protein and albumin) as well as lactate dehydrogenase $(\mathrm{LDH})$ were determined using a Beckman DXi automated analyzer (Beckman-Coulter). Haptoglobin was determined using Beckman Access/Array (Beckman-Coulter). 


\section{Echocardiography}

Transthoracic echocardiography was performed only in the 57 patients who agreed to undergo the test. Two-dimensional M mode and color Doppler images were obtained using Vivid-7 Cardiovascular Ultrasound System (GE Healthcare, Milwaukee, Wisc., USA). Echocardiographs were reviewed by a cardiologist (M.Z.). Cardiac dimensions were measured according to American Society of Echocardiography criteria [13].

Heart chamber dimensions, left ventricular posterior wall and interventricular septal thickness, ventricular function, left ventricular stroke volume, valve structure, and abnormal flow across the valves were recorded as previously described [14]. The TRJV was assessed in the parasternal right ventricular inflow, parasternal short-axis, and apical four-chamber views. Continuous-wave Doppler sampling of the peak TRJV was used to estimate the right-ventricular-to-right-atrial systolic pressure gradient with the modified Bernoulli equation [15]. For the purpose of analysis, PHT was defined as a peak TRJV of $\geq 2.5 \mathrm{~m} / \mathrm{s}$ as previously described.

The pulmonary artery pressure was estimated by measuring the TRJV using continuous-wave Doppler ultrasound. The PASP was quantitated by adding the Bernoulli-derived pressure gradient to the estimated mean right atrial pressure. The mean right atrial pressure was calculated according to the degree of collapse of the inferior vena cava with inspiration: $5 \mathrm{~mm} \mathrm{Hg}$ for a collapse of at least $50 \%$ and $15 \mathrm{~mm} \mathrm{Hg}$ for a collapse of less than 50\% [16]. PASP $\geq 30 \mathrm{~mm} \mathrm{Hg}$ was considered significantly high in our patient population.

\section{$6 M W$ Test}

The 6MW test was performed indoors, along a flat, straight, enclosed corridor with a hard surface. The walking course was $30 \mathrm{~m}$ in length [17]. Postwalk dyspnea and fatigue levels were recorded according to Borg's scale and the total distance walked was calculated. The transcutaneous arterial oxygen saturation was determined by pulse oximetry (BCI International, Waukesha, Wisc., USA) in the same setting.

\section{Statistical Analyses}

The statistical analysis was performed using IBM SPSS (Statistical Package for the Social Sciences) statistical software, version 19 (Chicago, Ill., USA). Data are presented as means \pm SD. Measurements were compared using Student's t test. Spearman's rank correlation coefficient was used to investigate the relation between various parameters. $\mathrm{p}<0.05$ was considered statistically significant. Regression analysis was used to identify the predictors of PASP in SCD patients.

\section{Results}

Of the 73 patients, $44(60.3 \%)$ and $29(39.75)$ had mild and severe courses of SCD, respectively. Four (5.4\%) had a history of ACS. None of the patients had a history of stroke or leg ulcers. Thirteen (17.8\%) patients were on hydroxyurea and $60(82.2 \%)$ were on no medication. The reticulocyte count, total bilirubin, and LDH levels were
Table 1. Echocardiographic findings in 57 SCD patients

Interventricular septum diameter, $\mathrm{mm}$

$9.6 \pm 0.9(9 \pm 1)$

Left ventricular internal diastolic dimension, $\mathrm{mm}$

$48.9 \pm 4.8(49 \pm 4)$

Left ventricular posterior wall dimension, $\mathrm{mm}$

$9.5 \pm 1.0(8 \pm 1)$

Left ventricular internal systolic dimension, $\mathrm{mm}$

$31.8 \pm 4.4(30 \pm 5)$

Left atrial diameter, $\mathrm{mm}$

Ejection fraction, \%

$34.5 \pm 4.6(39 \pm 5)$

TRJV, $\mathrm{m} / \mathrm{s}$

$63.9 \pm 6.3(58 \pm 7)$

PASP, $\mathrm{mm} \mathrm{Hg}$

$1.7 \pm 0.5(<2.5)$

$23.0 \pm 7.3(<30)$

Values are presented as means \pm SD. Values in parentheses are normal ranges.

Table 2. Echocardiographic abnormalities in SCD patients
Tricuspid regurgitation

Paradoxical septal motion

Mitral valve regurgitation, mild

Dilated left ventricle

Left ventricular wall hypertrophy

Dilated left atrium

Dilated right ventricle

Dilated right atrium

Aortic valve regurgitation

Mitral valve leaflet prolapse (anterior)

Mitral valve leaflet prolapse (posterior)

Mitral valve leaflet prolapse (anterior + posterior)

Values are presented as $\mathrm{n}(\%)$.
$14(24.6)$

0

$1(1.8)$

$1(1.8)$

0

0

0

$1(1.8)$

$6(10.5)$

$1(1.8)$

$1(1.8)$ significantly ( $\mathrm{p}<0.0001)$ higher in patients compared to controls, while $\mathrm{Hb}$ and haptoglobin levels were significantly $(\mathrm{p}<0.0001)$ lower in the former. Of the 73 patients, 51 (69.9\%) had HbSS while 22 (30.1\%) had $S \beta^{0}$ thalassemia. The mean $\mathrm{Hb}$ F level was $15.85 \%$ for the whole group; 2 (3\%) patients had $\mathrm{Hb}$ F levels $<5 \%$, while 18 (25\%) had levels $>20 \%$ regardless of whether or not they were receiving hydroxyurea therapy. Blood transfusion was rarely given to the patients, except perioperatively or, as in one patient, as a therapeutic modality for chronic priapism. The frequency of blood transfusions correlated negatively with the level of $\mathrm{HbF}(\mathrm{r}=-0.458$, $\mathrm{p}<0.0001)$ 
Table 3. Significant parameters in SCD patients with high and normal PASP

\begin{tabular}{lccl}
\hline & $\begin{array}{l}\mathrm{PASP}<30 \mathrm{~mm} \mathrm{Hg} \\
(\mathrm{n}=49)\end{array}$ & $\begin{array}{l}\mathrm{PASP} \geq 30 \mathrm{~mm} \mathrm{Hg} \\
(\mathrm{n}=8)\end{array}$ & $\begin{array}{l}\mathrm{p} \\
\text { value }\end{array}$ \\
\hline $\mathrm{RBC}, \times 10^{12} / 1$ & $3.96 \pm 0.81$ & $3.44 \pm 0.40$ & 0.011 \\
$\mathrm{Hb}, \mathrm{g} / \mathrm{l}$ & $107.13 \pm 15.20$ & $93.13 \pm 11.34$ & 0.010 \\
$\mathrm{Hct}, \mathrm{l} / \mathrm{l}$ & $0.32 \pm 0.05$ & $0.28 \pm 0.03$ & 0.006 \\
Reticulocytes, \% & $4.91 \pm 2.12$ & $6.91 \pm 1.32$ & 0.011 \\
\hline
\end{tabular}

Values are presented as means $\pm \mathrm{SD} . \mathrm{RBC}=$ Red blood cell count.

Table 4. $6 \mathrm{MW}$ test

\begin{tabular}{llll}
\hline & Patients & Controls & $\begin{array}{l}\mathrm{p} \\
\text { value }\end{array}$ \\
\hline $\begin{array}{c}\text { Systolic blood pressure, } \\
\text { mm Hg }\end{array}$ & $113.95 \pm 11.18$ & $120.23 \pm 14.06$ & 0.006 \\
$\begin{array}{c}\text { Diastolic blood pressure, } \\
\text { mm Hg }\end{array}$ & $66.40 \pm 7.86$ & $73.08 \pm 9.56$ & 0.000 \\
$\begin{array}{c}\text { Distance walked in } \\
\quad \text { min, m }\end{array}$ & $384.63 \pm 73.07$ & $531.76 \pm 83.92$ & 0.000 \\
$\begin{array}{c}\text { Heart rate at } \\
\text { baseline, bpm }\end{array}$ & $88.72 \pm 12.37$ & $84.48 \pm 12.68$ & 0.060 \\
$\begin{array}{l}\text { Heart rate at the end } \\
\text { of the test, bpm }\end{array}$ & $109.90 \pm 18.79$ & $115.02 \pm 19.19$ & 0.133 \\
$\begin{array}{c}\text { Oxygen saturation at } \\
\text { baseline, \% }\end{array}$ & $96.92 \pm 2.36$ & $98.00 \pm 1.20$ & 0.002 \\
$\begin{array}{l}\text { Oxygen saturation at } \\
\text { the end of the test, \% }\end{array}$ & $96.15 \pm 2.72$ & $97.88 \pm 1.44$ & 0.000 \\
\hline
\end{tabular}

Values are presented as means $\pm \mathrm{SD}$.

\section{Echocardiography}

The measured parameters of echocardiography and the frequencies of abnormal findings are shown in tables 1 and 2 . Of the 57 patients who underwent an echocardiographic study, 14 (24.5\%) had mild tricuspid regurgitation while $15(26 \%)$ had mild mitral valve regurgitation, which was the most common abnormality. The mean ejection fraction of the study group was $63.9 \pm 6.3 \%$. The mean TRJV was $1.7 \pm 0.5 \mathrm{~m} / \mathrm{s}$. Three (5.2\%) patients (all $\mathrm{HbSS}$ ) had mildly raised TRJV $(2.6-2.97 \mathrm{~m} / \mathrm{s})$. Of these 3 patients, 2 died 10 months and 3 years after the test, respectively. Both had nonsevere vaso-occlusive crises. The first patient, a 23-year-old morbidly obese (BMI 60.6) female with diabetes and hypertension, had low $\mathrm{Hb}$ levels, a high reticulocyte count and transfusion requirement; her $\mathrm{Hb} \mathrm{F}$ level was $4 \%$ and her oxygen saturation was $98 \%$. The second patient, a 66-year old female diabetic with breast cancer, had similar enhanced hemolytic parameters. Her oxygen saturation was $90 \%$ at baseline and dropped to $86 \%$ after the $6 \mathrm{MW}$ test. Both patients had high $\mathrm{Hb}$ F levels (>15\%) before treatment with hydroxyurea. If the first patient is considered an outlier because of a very high BMI, the age of the patients with high TRJV was significantly higher than that of patients with TRJV $<2.5 \mathrm{~m} / \mathrm{s}(\mathrm{p}=0.005)$. The third patient with a high TRJV had severe vaso-occlusive crises and was receiving maintenance therapy with hydroxyurea.

The mean PASP of the patients was $23.0 \pm 7.3 \mathrm{~mm} \mathrm{Hg}$. Eight (14\%) patients, including the 3 with TRJV $\geq 2.5 \mathrm{~m} / \mathrm{s}$, had high PASP $(\geq 30 \mathrm{~mm} \mathrm{Hg})$; the mean was $35.3 \pm 5.1$ $\mathrm{mm} \mathrm{Hg}$. $\mathrm{Hb}$ and hematocrit (Hct) were significantly lower in patients with high PASP, while reticulocyte count was significantly higher (table 3). Binary logistic regression analysis showed that lower Hb levels were significantly associated with a high PASP (OR $0.928,95 \%$ CI $0.870-0.990 ; \mathrm{p}=0.023)$. The 57 patients had normal right ventricular size and none had paradoxical septal motion.

\section{$6 M W$ Test}

The systolic and diastolic blood pressure, oxygen saturation before and after 6MW test, and distance walked were significantly lower in SCD patients compared to controls (table 4). The 8 patients with high PASP had a mean $6 \mathrm{MW}$ distance of $393.8 \pm 89.7 \mathrm{~m}$ compared to 380.7 $\pm 69.8 \mathrm{~m}$ in patients with normal PASP, which was not significantly different $(\mathrm{p}=0.706)$.

\section{Discussion}

In the present study, the clinical manifestations in the group of SCD patients were mild to moderate in relation to the frequencies of vaso-occlusive crises, hospital admissions, and blood transfusions. None of the patients had a history of stroke or leg ulcers. However, there was laboratory evidence of chronic hemolysis with low $\mathrm{Hb}$ and Hct and high reticulocyte counts, $\mathrm{LDH}$, and bilirubin in comparison to controls.

Although the gold standard for the diagnosis of PHT is cardiac catheterization, a TRJV $\geq 2.5 \mathrm{~m} / \mathrm{s}$ correlates well with the diagnosis [18]. While the precise prevalence of PHT is unknown, reported estimates range from 5 to $30 \%$ in adult SCD patients [19-21]. In a study by Gladwin et al. [1], PHT reflected by the TRJV was estimated to be present in $32 \%$ of patients with SCD, while other studies 
have yielded rates of $30-56 \%[22,23]$. In the present study, the mean TRJV was $1.7 \mathrm{~m} / \mathrm{s}$ compared to $2.7 \mathrm{~m} / \mathrm{s}$ in a recent large prospective multicenter study of American patients [24]. Strikingly, only 3 (5.2\%) of the Kuwaiti patients included in this study had TRJV values $\geq 2.5 \mathrm{~m} / \mathrm{s}$, and 2 of them died 10 months and 3 years after the study, respectively. No other deaths had been reported in the cohort at the time of reporting. The fact that patients with high PASP had significantly impaired hemolytic indices (low $\mathrm{Hb}$ and $\mathrm{Hct}$ and higher reticulocyte counts) is consistent with the realization that hemolysis aggravates vasculopathy and predisposes to PHT [18]. Both mortalities in this cohort occurred soon after documentation of a raised TRJV. However, this is consistent with the rarity of hemolysis-driven chronic vasculopathy among patients with raised $\mathrm{Hb} F$ levels in whom the vaso-occlusive phenotype is more common such that avascular necrosis is the major complication encountered [8].

The use of echocardiography to estimate PASP has been validated in patients with SCD and it correlates well with values obtained by right heart catheterization [1]. Eight (14\%) patients (including the 3 with a high TRJV) had high PASP, i.e. $\geq 30 \mathrm{~mm} \mathrm{Hg}$, that correlated with the severity of anemia. The $6 \mathrm{MW}$ test is a surrogate for functional capacity, or exercise tolerance, and it correlates well with the elevation of pulmonary artery pressure and pulmonary vascular resistance [25]. When interpreting this test in SCD, certain noncardiopulmonary factors such as concurrent pain and avascular necrosis of the hip must be considered as these can interfere with the performance of the test. This may explain why our patients with high PASP in the present study had 6MW distance not significantly different from the distance walked by patients with normal PASP. However, when patients were compared to controls they had significantly lower $6 \mathrm{MW}$ distance.

The patients in this study had some degree of hemolysis, as shown by the relatively high levels of reticulocytes and $\mathrm{LDH}$, and appropriate efforts should be made to identify those at risk for associated complications. Since PHT is a poor prognostic indicator of SCD, it would appear that PASP and TRJV might be noninvasive tests that can be used for screening Kuwaiti patients with SCD.

\section{Conclusion}

Raised PASP was common in the Kuwaiti patients with SCD while raised TRJV was not. Hence, the value of PASP as an earlier indicator of poor prognosis needs to be evaluated further.

\section{Acknowledgment}

This project was supported by Kuwait University research grant No. MG03/08.

\section{References}

1 Gladwin MT, Sachdev V, Jison ML, et al: Pulmonary hypertension as a risk factor for death in patients with sickle cell disease. N Engl J Med 2004;350:886-895.

$\longrightarrow 2$ Siddiqui AK, Ahmed S: Pulmonary manifestations of sickle cell disease. Postgrad Med J 2003;79:384-390.

3 Chin KM, Rubin LJ: Pulmonary arterial hypertension. J Am Coll Cardiol 2008;51:15271538.

4 ATS Committee on Proficiency Standards for Clinical Pulmonary Function Laboratories: ATS statement: guidelines for the six-minute walk test. Am J Respir Crit Care Med 2002; 166:111-117.

5 Machado RF, Martyr S, Kato GJ, et al: Sildenafil therapy in patients with sickle cell disease and pulmonary hypertension. Br J Haematol 2005; 130:445-453.

6 Adekile AD: Sickle cell disease in Kuwait. Hemoglobin 2001;25:219-225.
Adekile AD, Gu LH, Baysal E, et al: Molecular characterization of alpha-thalassemia determinants, beta-thalassemia alleles, and beta $\mathrm{S}$ haplotypes among Kuwaiti Arabs. Acta Haematol 1994;92:176-181.

-8 Marouf R, Gupta R, Haider MZ, et al: Avascular necrosis of the femoral head in adult $\mathrm{Ku}$ waiti sickle cell disease patients. Acta Haematol 2003;110:11-15.

-9 Al-Kandari FA, Owunwanne A, Syed GM, et al: Regional cerebral blood flow in patients with sickle cell disease: study with single photon emission computed tomography. Ann Nucl Med 2007;21:439-445.

10 Marouf R, Gupta R, Haider MZ, et al: Silent brain infarcts in adult Kuwaiti sickle cell disease patients. Am J Hematol 2003;73:240243.

11 Adekile AD, Haider MZ: Morbidity, beta S haplotype and alpha-globin gene patterns among sickle cell anemia patients in Kuwait. Acta Haematol 1996;96:150-154.
2 Williams JR: The Declaration of Helsinki and public health. Bull World Health Organ 2008; 86:650-652.

13 Guyatt GH, Thompson PJ, Berman LB, et al How should we measure function in patients with chronic heart and lung disease? J Chronic Dis 1985;38:517-524.

14 Schiller NB, Shah PM, Crawford M, et al: Recommendations for quantitation of the left ventricle by two-dimensional echocardiography. American Society of Echocardiography Committee on Standards, Subcommittee on Quantitation of Two-Dimensional Echocardiograms. J Am Soc Echocardiogr 1989;2: 358-367.

15 Appleton CP, Jensen JL, Hatle LK, et al: Doppler evaluation of left and right ventricular diastolic function: a technical guide for obtaining optimal flow velocity recordings. J Am Soc Echocardiogr 1997;10:271-292. 
16 Berger M, Haimowitz A, Van Tosh A, et al: Quantitative assessment of pulmonary hypertension in patients with tricuspid regurgitation using continuous wave Doppler ultrasound. J Am Coll Cardiol 1985;6:359-365.

17 D’Alonzo GE, Barst RJ, Ayres SM, et al: Survival in patients with primary pulmonary hypertension: results from a national prospective registry. Ann Intern Med 1991;115:343349.

18 Gladwin MT, Vichinsky E: Pulmonary complications of sickle cell disease. N Engl J Med 2008;359:2254-2265.
19 Sutton LL, Castro O, Cross DJ, et al: Pulmonary hypertension in sickle cell disease. Am J Cardiol 1994;74:626-628.

20 Castro O: Systemic fat embolism and pulmonary hypertension in sickle cell disease. Hematol Oncol Clin North Am 1996;10:12891303.

21 Al-Sukhun S, Aboubakr SE, Girgis RE, et al: Pulmonary hypertension is present in 10 $30 \%$ of adult patients with sickle cell disease. Blood 2000;96:9A.

22 Aboubakr SE, Girgis R, Swerdlow PS: Pulmonary hypertension in sickle cell disease. Am J Respir Crit Care Med 1999;160:A144.

23 Ahmed S, Siddiqui AK, Sadiq A, et al: Echocardiographic abnormalities in adult patients with sickle cell disease. Blood 2002;100:453a454a.
24 Sachdev V, Kato GJ, Gibbs JS, et al: Echocardiographic markers of elevated pulmonary pressure and left ventricular diastolic dysfunction are associated with exercise intolerance in adults and adolescents with homozygous sickle cell anemia in the United States and United Kingdom. Circulation 2011;124: 1452-1460.

25 Anthi A, Machado RF, Jison ML, et al: Hemodynamic and functional assessment of patients with sickle cell disease and pulmonary hypertension. Am J Respir Crit Care Med 2007;175:1272-1279. 